\title{
Complexity in Supply Chains: A New Approach to Quantitative Measurement of the Supply-Chain-Complexity
}

\author{
Filiz Isik \\ Bergische Universität Wuppertal Schumpeter School of Business and Economics \\ Chair of Business Computing and Operations Research
}

Germany

\section{Introduction}

The increasing globalization of market is forcing hard competition, consequently resulting increased complexity in supply chains. Complexity has many negative effects (consequences) on supply chains such as high operational costs, customer dissatisfaction, time delay in delivery, excess inventory or inventory shortage (stockouts), lack of cooperation, collaboration and integration among supply chain participants etc. A supply chain consists of multiple business partners who work together directly or indirectly which is collaborated by information, material and financial flows. These flows may lead to high complexity due to the lack of information (distorted information) within supply chain participants. Uncertainty variety, diversity, numerousness etc. are some of the factors which lead to the variation between expected (planed, scheduled) and actual flows and this variation called as complexity in this present study. These factors can be originated from exogenous and/or endogenous drivers. Therefore, supply chain complexity (SCC) can be classified into two general types as internal and external from its sources. Supply chain complexity is closely correlated with total supply chain management cost. Any increase in complexity level in a supply chain has a relevant contribution to its total cost. Complexity can be reduced by an effective complexity management that provides costs reduction within supply chains.

In order to manage complexity in supply chains effectively and efficiently, a four stage complexity management model is proposed to use which covers identifying, measuring, analyzing and controlling (reducing and avoiding) of complexity. After defining the complexity clearly, it is recommended to be measured so as to identify it quantitatively so that it can be analyzed, reduced and avoided. Defining the root causes of the complexity is required to improve the system complexity. However, complexity may result excess inventory which can be sometimes useful for the company, if a customer wants to pay for it. Otherwise high complexity is required to be reduced because of its high costs to the company.

With respect to obtaining a quantitative measure, complexity in supply chains is defined as the quantitative variations (deviations) between actual and predicted flows caused by uncertainty and variety through material and information flows. Regarding the definition of complexity in this study, complexity will be measured by using a new proposed entropy measure based on Shannon information entropy (Shannon, 1948) which is a measure of the average uncertainty or information associated with random variable. 
Complexity as a concept of manufacturing has been studied by several researchers. For example, Wilding (1998) used a 'supply chain complexity triangle' which includes deterministic chaos, parallel interactions and demand amplification to understand the generation of uncertainty within supply chains. Calinescu et al. (2001) analyzed the manufacturing complexity by categorizing it into three; decision-making complexity, structural complexity and behavioural complexity. Milgate (2001) described uncertainty, technological intricacy and organizational system as dimensions of supply chain complexity so as to manage it. In order to manage complexity in manufacturing effectively and efficiently, understanding and measuring complexity are required. This study focuses on the measurement of the supply chain complexity associated with uncertainty and variety by information and material flows based on a new modified entropy measure.

Entropy is commonly known as a measure of the energy dispersal for a system in thermodynamics (second law of thermodynamics). However, Shannon (1948) and Shannon and Weaver (1949) studied the entropy from a statistical perspective which evaluates uncertainty (associated with random variables) in a system by measuring the information content within this system. His famous approach is called as Shannon's information entropy in the relevant literature.

The academic survey on entropy measure from its statistical aspect has begun with Yao (1985) who studied the entropy as a measure of flexibility. Later, Deshmukh et al. (1992) presented a static measure of complexity based on entropy method. Ronen and Karp (1994) developed an approach that determines the location of a lot by using entropy measurement. Entropy as a measure of complexity in supply chains was first introduced by Frizelle and Woodcock (1995). Later, Sivadasan et al. (2002), Deshmukh et al. (1998) and Sivadasan et al. (2006) studied their approach with an industry practice done by the Institute for Manufacturing (IFM) at Oxford and Cambridge universities (see website www.ifm.eng.cam.ac.uk/csp/projects/complexschain.html). Their papers present an entropy-based approach in more detail and defined structural (deals with variety (schedule) and operational (deals with uncertainty (deviation from the schedule)) complexity measures by extending Shannon information entropy. In their work, complexity is considered as a random variable with different states and corresponding probabilities for each state. Based on their work Makui and Aryanezhad (2003) presented a new approach which developed a static complexity measure based on entropy. Martinez-Olvera (2008) developed a methodology based on entropy measure to compare different supply chain information sharing by using computer simulation.

Later, Isik (2010) provided their approach and modified the complexity measures. In prior entropy-based works on complexity (Shannon, 1948; Shannon and Weaver, 1949; Frizelle Woodcock, 1995; Sivadasan et al., 2002; Sivadasan et al., 2006), it is argued that complexity (or entropy) is only a function of probabilities of different states. However, Isik (2010) argues that complexity is not only a function of probabilities of different states, but also each state can have different complexity levels of its own that needs to be considered. As a contribution of the new approach, an "expected value" is defined for each state and the deviation from that expected value is measured. This study presents her work with an example given which measures complexity (variations) between actual and scheduled demand levels.

This study is organized as follows. Section 2 presents supply chain complexity, its characteristics and classification of complexity sources in supply chains. Section 3 is considered complexity management in supply chains. Complexity measurement is represented by section 4 . Section 5 demonstrates a case study about complexity measurement. Section 6 concludes this study. 


\section{Complexity and supply chain complexity}

Manufacturing is becoming more complex than ever in the last decade due to the globalizations and its effect. Increasing complexity of supply chains leads to high operational costs which have to be reduced to be able to manage by an effective collaboration among supply chain partners. The sources of the complexity may occur from external and/or internal drivers. Therefore, understanding and measuring complexity are becoming increasingly important from the managerial side of the organizations to cope with this complexity. Although, complexity is very difficult to define formally, there are some definitions of complexity in the relevant literature. A suitable one of them regarding the present study is as follows:

"Complexity is being marked by an involvement of many parts, aspects, details, notions, and necessitating earnest study or examination to understand or cope with (Webster's Third International Dictionary, Gove 1986)".

In order to measure complexity in supply chains, the data used is required to be quantitative. Regarding the definition above and referring to the goal of this study, complexity can be defined as quantitative differences between predicted and actual states which are associated with uncertainty and/or variety caused by internal and external drivers in a (supply chain) system.

A supply chain consists of many participants which collaborate directly or indirectly to fulfil customer demand along the supply chain. Within each organization in a supply chain, a participant receives demands from the prior downstream stage and places orders with the next upstream stage to be able to supply the downstream customer demands (see figure 1). All these activities are operated by the flows (information, material and financial) in a typical supply chain. Information and/or material flows along the supply chain systems are the main complexity drivers which have to be managed effectively and efficiently. Each participant within a supply chain has its own prediction on demand (forecast) based on the present demand received from its downstream customer so as to supply the required product (or service) to this customer. Figure 1 is illustrated to demonstrate a simple three stage supply chain and its flows. Some forecasting methods used to predict the demand by using historical demand data (moving average, exponential smoothing method, autoregressive integrated moving average models (for example see Montgomery et al., 2008). However, forecasting has always a misleading associated with uncertainty which cause mismatch between planed and actual demand values. This costly mismatch is related

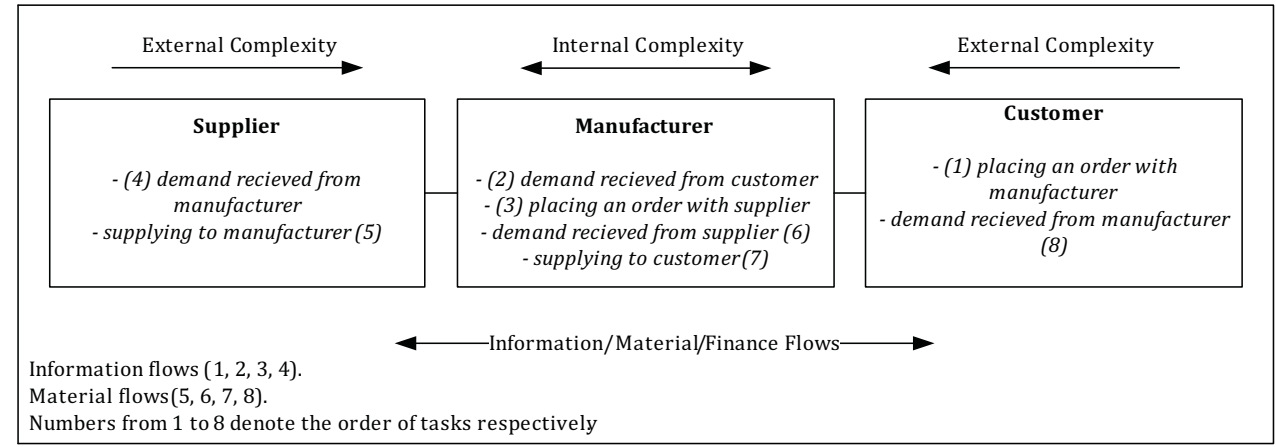

Fig. 1. Flows in a supply chain. 
with what planed (predicted or forecasted) and what actually received. These quantitative differences (variations) between actual and predicted values are called as complexity in this study.

Regarding this study, a supply chain complexity can be defined as whole operational, structural and behavioural variations caused by uncertainties and/or varieties which occurs expectedly (predicted) and/or not expectedly (unpredicted) through internal or external drivers along a supply chain system.

\subsection{Characteristic of the supply chain complexity}

A system consists of many parts or elements of various types which are linked each other directly or indirectly. These various elements and their interrelationships are significant for complexity occurring in a system. Furthermore, a supply chain is a complicated system due to the uncertain manufacturing environment, so complexity presented in this study is interpreted as a system complexity. There are some key characteristics (dimensions) of complexity occurring in a supply chain system which need to be discussed to understand the impact of these characteristics on the occurrence of complexity. However, the key dimensions may act on each other or one another. Therefore, the explanations of these dimensions do not only represent the value itself, but also highlight the relationship and interaction between the characteristics of the complexity.

Numerousness: This characteristic of the complexity covers the number of components such as items (raw, manufactured or end), products, processes, supply chain participants such as customers or suppliers, relationships, interactions, goals, locations, etc. A high number level of any components contributes increasingly complexity in a supply chain system. In order to deal with this characteristic, it is only required to reduce the level of number. The changeability of number under any consideration is directly related with any change in complexity level.

Diversity: Diversity is related with the homogeneity or heterogeneity of a system. A high (or low) level of diversity of any components such as customer, product or transport channels along the supply chains leads to system`s heterogeneous (or homogeneity) and results a high (or low) level of complexity.

Interdependency: Interdependence covers the intended or unintended relationship between at least two (or more) states such as items, products, processes, supply chain participants etc. which may cause complexity in a system. Interdependence states cannot be operated without each other or without any influence from each other. Complexity increases in direct proportion to the increase of Interdependence.

Variability: Variability refers to a state characteristic of being changeable where an event produces possible different outcomes in a system. A variable system represents rapidly changeable element over time. E.g. consumers change their mind unexpectedly over time which results a change in product specifications. Any increase in variability causes increased complexity in a system. From the supply chain side, variability considers measurable (quantitative) variations between the expected and actual states in a system.

Variety: Variety is linked with a state of being various. A variable system consists of elements or components which are different from each other. For example, a product or a process variety in supply chains leads to increase in complexity level over time. Variety represents dynamical behaviour of a system.

Uncertainty: Uncertainty represents all difficulties to be able to make a clear picture of a system due to the lack of information or knowledge. Systems`deficits such as indefiniteness, 
risks, ambiguities or ambivalences, connectedness lead to high level of uncertainty in a system. Uncertainty and complexity are linked very closely each other. The more uncertainty in a supply chain system is, the more complexity occurs in this system. The most common effect of uncertainty that causes complexity is well known as the "bullwhip effect" in the literature. As a future work, complexity measuring in bullwhip effect will be discussed in more detail.

The complexity characteristics presented above can be closely related to each other, one can effect the others or one can cause the occurring of the others. The each characteristic has not the same effect (more or less) on a supply chain system with or without any interactions or interrelationships between them. For example, a high level of variety may cause variability in a system or high density of diversity may lead to uncertainty. If the level of these characteristics is reduced, complexity will be reduced as well. However, this study only concentrates on the uncertainty, variability and variety with respect to complexity measurement based on entropy so the other complexity characteristics will not discussed in more detail.

\subsection{Classification of supply chain complexity}

Various sources involve complexity in supply chains. Material and information flows represent the main complexity drivers along a supply chain due to the factors such as uncertainty, variability, size, speed, diversity etc. A supply chain consists of exogenous and endogenous interactions and interrelationships which cause increase in complexity, resulting unpredictability in a system. Companies need to cope with this increasing complexity from both internal and external side to compete better in global market. Therefore, supply chain complexity can be classified into two general types from its sources:

- internal supply chain complexity drivers

- $\quad$ external supply chain complexity drivers

Organizations have to reduce and avoid both internal and external complexity, so as to obtain more reliable, more predictable and less complex system. Both internal and external sources may be originated from operational, structural and behavioural uncertainties in a supply chain system.

Internal SCC drivers: Internal complexity is associated with material and information flows within single business partner of a supply chain. This type of complexity is related with the structure of this single business partner, which covers such as process, product, production and organizational uncertainties. Some specific examples for internal supply chain complexity are process deficits, material shortfall, machine breakdowns, lack of management, large product variety, etc. Internal drivers can be reduced and avoided by improving information and material flows within the single business partner.

External SCC drivers: External complexity driver is related with material and information flows exported by other business partners (customer and supplier) to a single business partner in a supply chain. Globalisation, technological innovation, high competition and customer demand variety are some of the external drivers of the supply chain complexity. External supply chain drivers can be reduced and avoided by more corporations between the partners to get a more reliable system.

However, from the measurement aspect of a supply chain complexity, a measurement of complexity can be considered the whole system which may be called total SCC. 


\section{Complexity management in supply chains}

Globalizing supply chains drive complexity which needs to be managed effectively and efficiently to reduce high costs and to improve operating performance in many industries. Complexity is too difficult to eliminate entirely by organizations but they can bring it under control and avoid it in the future by an efficient and effective management system. Supply chain complexity can be effectively managed by four strategies/steps: namely, identifying, measuring, analyzing and controlling (reducing and avoiding). The all strategies are related to each other and have closely interactions and interrelationships. Figure 2 illustrates the complexity management stages in a supply chain.

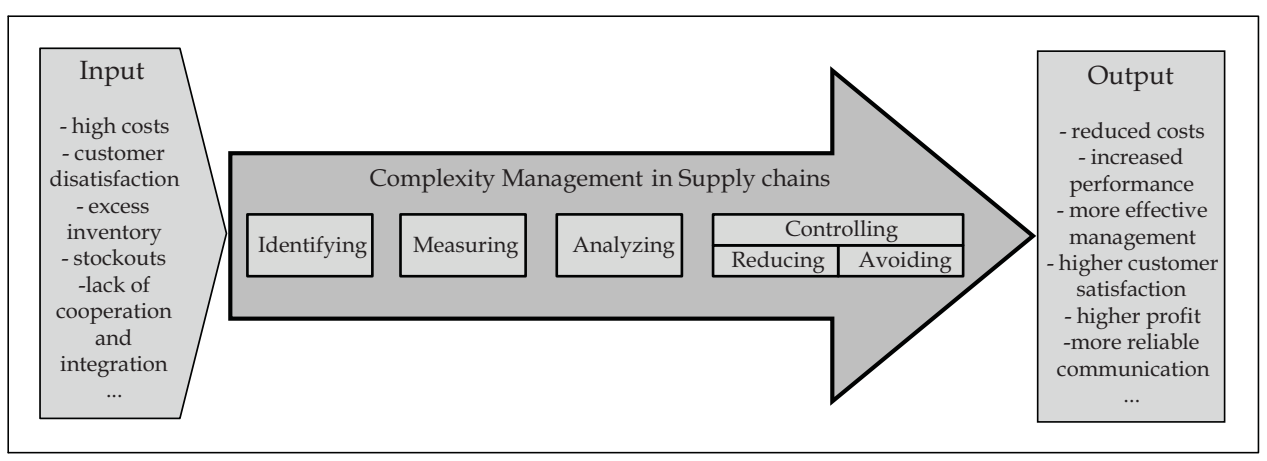

Fig. 2. Steps of a complexity management in supply chains.

Identifying: Identifying is the first step to begin in order to manage the complexity in supply chains efficiently and effectively. Therefore, it is first recommended to accept existence of the complexity by managers before coping with this complexity. Complexity is defined as all quantitative variations between planed and actual flows along a supply chain in this study. Bringing the complexity to light help the manager to detect how big the variations between the actual flows and the expected flows which lead to high operational costs.

The complexity sources of all variations and their interdependencies and interrelationships to each other should be clearly defined, resourced and recorded at this stage to be able to prove their solutions later. The sources can be categorized according to potential reasons. For example, external resources can be originated from supplier or from customer; internal factors can be related with such as machine, laboratory, process, people etc.

Measuring: After defining the complexity, it is first recommended to measure it, in order to dedicate how the system behaves. Therefore, regarding the definition of the complexity in this study, entropy is used as a measure for complexity. Measuring complexity will be discussed in more detail in section 4 .

Analyzing: After the measuring step, the results of the complexity measures are needed to be analyzed. Analyzing complexity values is related with the aim of the measuring. A measurement can be analyzed from many perspectives. For example, a complexity measure can be implemented for

- analyzing internal, external and total complexity of a supply chain from its sources,

- comparing the supply chain flows (material and/or information) E.g. same products on different product lines, different products on the same line,

- comparing the performance among various supply chain partners, etc. 
In this step the root causes of the complexity and their costs in a supply chain can be analyzed to detect the countermeasures regarding this complexity as well. Some problem solving methods (such as brainstorming, cause and effect analyze, root cause analysis, etc.) can be used for analyzing the root causes of the complexity occurring in a system.

Controlling: Controlling is a fundamental step of the management and it is related with taking complexity under control. Complexity is not only needed to be reduced, but also it is required to be avoided so as to prevent against its existence in the future. Therefore, the step controlling consists of two parts: namely, reducing and avoiding. Improving of information sharing within supply chains can mitigate the high complexity and help reducing the costs. Hence, effective and efficient use of IT tools and methods can help the controlling complexity in supply chains. These tools do not only improve information quality, but also they integrate supply chain`s participants.

Reducing: Complexity is not always easy to remove completely from the system. Thus, it needs to be considered to reduce as much as possible. Reducing complexity is a cost-based strategy for the realisation of supply chain management. The strategy of reducing supply chain complexity includes the improving material and information flows along the supply chains. Hence, an integrated complexity management is required by standardisation (for example ISO quality assurance standards) and harmonisation of interfaces between information, material and financial flows in order to decrease level of complexity, reduce costs and improve supply chain` efficiency. Therefore, not only the supply chain flows, but also the processes, business partners, product and production planning, logistic activities, services stand etc. are needed to be improved by integrated complexity management. However, a SCOR model (The supply-chain operations reference model) can be used to reduce complexity. A supply chain partner typically operates five basic business processes (plan, source, make, deliver, and return) in this model. These processes will not be discussed in detail in this study. Authors like Lee et al. (1997a) and Lee et al. (1997b) offer some countermeasures to reduce uncertainty in supply chains.

Avoiding: The aim of an efficient complexity management in supply chains does not only cover the reduction in complexity level by taking corrective actions, but also it comprises avoiding of the complexity by preventive actions in the future. For example, ISO standardizations, total quality management, six sigma and lean production management can be used to avoid supply chain complexity in the future (for example see Martin, 2007; Hoyle, 2009). Improved communication between partners of supply chains and continuous training of the people can corroborate the preventive actions as well.

Each step is very significant to complexity management in supply chains. Amount of four management's stages, measuring is the key stage to be able to realize the other stages effectively. Therefore, this study present a measurement method based on entropy method and it is presented in the next section.

\section{Measuring supply chain complexity based on entropy measurement}

In order to manage complexity in manufacturing, measurement is required. The aim of the complexity measurement is to be able to obtain a numerical scale to compare the complexity values of a system on different problems. Therefore, an information theoretic measure called classical entropy measure(s) in this study according to Calinescu et al. (2000), Sivadasan et al. (2002) and Sivadasan et al. (2006) based on Shannon's information theory (Shannon 1948) and a new proposed entropy measure(s) according to (Isik, 2010) are presented to measure complexity behaviour between two supply chain participants. 


\subsection{Classical entropy measure}

The concept of entropy is known as the second law of thermodynamics and was first introduced by the German physicist Rudolf Julius Emmanuel Clausius (1822-1888). Scientists such as James Clerk Maxwell (1831-1879), Josiah Willard Gibbs (1839-1903), Ludwig Eduard Boltzmann (1844-1906), and Claude Elwood Shannon, (1916-2001) studied entropy from a statistical aspect. Shannon (1948) described the entropy as a measure of information or uncertainty on random variables, which take different probabilities among the states into account. The average uncertainty associated with an outcome is represented by discrete random variable $X$ on a finite set $X=\left\{x_{1}, \ldots, x_{n}\right\}$ with probability distribution function $p\left(x_{i}\right)$ being in state $i,(i=1, \ldots, n)$. The Shannon's information entropy $H(X)$ of $X$ is defined as

$$
H(X)=-\sum_{i=1}^{n} p\left(x_{i}\right) \log _{2} p\left(x_{i}\right)
$$

Shannon used logarithm to the base 2 in the entropy formula to give entropy the dimension of a binary digit (bit). The Shannon's entropy represents the following properties (Shannon, 1948; Shannon and Weaver, 1949).

- $\quad p\left(x_{i}\right)=1 / n, \mathrm{n}$ represents the number of possible outcomes in a system

- Information is a non-negative quantity: $H(X) \geq 0$, since $0 \leq p\left(x_{i}\right) \leq 1$.

- $\quad$ The sum of all probabilities equals $1: \sum_{i=1}^{n} p\left(x_{i}\right)=1$

- $\quad$ If an event has probability 0 , then the entropy is also zero.

- Entropy achieves its maximum value $\left(H(X)=\log _{2} n\right)$ when all outcomes occur with

the same probability $\left(p\left(x_{i}\right)=\frac{1}{n}\right)$, (all outcomes are equal likely) so the system is being in most uncertain and unpredictable states.

- Entropy attains its minimum value $(H(X)=0)$ when only one outcome occurs with probability $1\left(p\left(x_{i}\right)=1\right)$ which means outcome is known with complete certainty, then there is least information occurrence in a system.

This study focuses on the measurement of complexity in manufacturing based on Shannon's information entropy. Frizelle and Woodcock (1995), Deshmukh et al. (1998), Calinescu et al. (2000), Sivadasan et al. (2002) and Sivadasan et al. (2006) introduced entropic measurement for manufacturing complexity by using Shannon's entropy. Complexity can be divided into two: namely, structural (static) and operational (dynamic).

Structural (static) complexity is defined as the expected amount of information required to define the state of a system for a given period. Structural complexity is related with the information in the schedule and it is associated with variety amount of the complexity characteristics (see section 2.1) in a system which can be written as follows (Frizelle and Woodcock 1995; Sivadasan et al. 2002; Deshmukh et al. 1998):

$$
H_{(s)}^{I}=-\sum_{i=1}^{M} \sum_{j=1}^{N} p_{i j} \log _{2} p_{i j}
$$

where 
$H_{(s)}^{I} \quad$ : Structural complexity

$p_{i j} \quad$ : Probability of resource $i,(i=1, \ldots, M)$ being in state $j,(j=1, \ldots, N)$

M : Number of resources

$N \quad$ : Number of possible states for resource $i$

Operational (dynamic) complexity is considered as the expected amount of information required to define deviation from the schedule due to uncertainty characteristic of complexity. Operational complexity is related with the monitoring of planned and unplanned events and it can be defined as (Frizelle and Woodcock 1995; Deshmukh et al. 1998; Sivadasan et al. 2002):

$$
H_{(o)}^{I}=-(1-P) \sum_{i=1}^{M} \sum_{j=1}^{N} p_{i j} \log _{2} p_{i j}
$$

where

$$
\begin{array}{ll}
H^{I}{ }_{(o)} & \text { : Operational complexity } \\
P & : \text { Probability of the system being "in control (scheduled)" state } \\
(1-P) & \text { : Probability of the system being "out of control (unscheduled)" state }
\end{array}
$$

\subsection{New proposed/modified entropy measure}

Focus of this study is to present the superiority of the new proposed entropy measures by modifying classical complexity measures based on entropy. The classical measures have some drawbacks to be improved. They indicate that complexity is only a function of different state. Whereas, Isik (2010) proposes, each state can have its own expected outcome value for the state in a system which is needed to be considered. Because each state has different cost level that has to be taken into consideration as well. The costs are not only related with complexity cost to organizations but also its countermeasure's costs due to the corrective and avoiding actions. According to classical approaches, two different states with the same probabilities of occurrence but with different cost levels can have the same entropy or complexity level. From a point of view of cost effect, the larger distance to the expected outcome value has to produce a greater complexity value because larger distances to the expected outcome value have a larger effect on the system than the smaller distances. Therefore, the classical measures are needed to be expanded to cover a contribution of the expected value as well. The expected outcome value needs to be defined with respect to the problems which will be addressed. Complexity in this paper is defined as a variation between predicted and actual flows. Therefore, the existence of variation between planned and actual demand shows complexity existence. If the variation between demand flows equal zero, then there is no complexity occurring. In manufacturing systems it is expected that there is no variation between predicted and actual flows (ideal case). I.e. there is no deviation from the schedule. Therefore the expected outcome value for this study is zero. However, the expected value can be also some tolerated variation between expected and actual flows in manufacturing system according to the problem structure. The corresponding deviation from that expected value shows the complexity of that particular state (Isik, 2010).

As a contribution of the new complexity approach, an expected outcome value is defined for each state and the deviation $\left(d_{i}\right)$ from that expected value is measured. 
The new modified entropy measure can be defined as follows:

$$
H^{I}=-\sum_{i=1}^{n}\left[\log _{2} p_{i}\right] p_{i} d_{i}
$$

The new modified structural complexity can be defined as follows:

$$
H_{(s)}^{I I}=-\sum_{i=1}^{M} \sum_{j=1}^{N}\left[\log _{2} p_{i j}\right] d_{i j} p_{i j}
$$

The new modified operational complexity can be defined as follows:

$$
H_{(o)}^{I I}=-(1-P) \sum_{i=1}^{M} \sum_{j=1}^{N}\left[\log _{2} p_{i j}\right] d_{i j} p_{i j}
$$

where $\left(d_{i j}\right)$ (absolute value of $\left(d_{i j}\right)$ is considered) is the deviation of outcomes from the expected outcome value for the state.

\section{A case study}

Complexity in supply chains is associated with material and information flows between supply chain partners. In this case study, a single supplier-customer system is considered which is illustrated in figure 3. In this present example, the supplier has its own forecast demand level (expected values of demand) and the customer places order (actual demand values) with its supplier. Therefore, the variations between actual and scheduled demand levels will be analyzed to address how much the scheduling goal on demand of the supplier is achieved. Monthly predicted and actual demand values are created as a simple example to show how to use the entropy-based complexity measure in manufacturing (see table 1).

\begin{tabular}{|c|c|c|}
\hline $\begin{array}{c}\text { Supplier } \\
\text { Scheduled } \\
\text { demand }\end{array}$ & Material flow & $\begin{array}{c}\text { Customer } \\
\text { Actual } \\
\text { demand }\end{array}$ \\
\hline
\end{tabular}

Fig. 3. A single supplier-customer system.

In order to illustrate the variations between actual and expected flows, the curves of actual and scheduled demand values are plotted in figure 4.

The entropic complexity measurement includes three steps below.

\section{Calculation of the variation}

As a first step of the complexity measure the quantitative differences (variations) between actual and scheduled demand values are calculated by subtracting actual values from expected values and seen in variation column in table 1. 


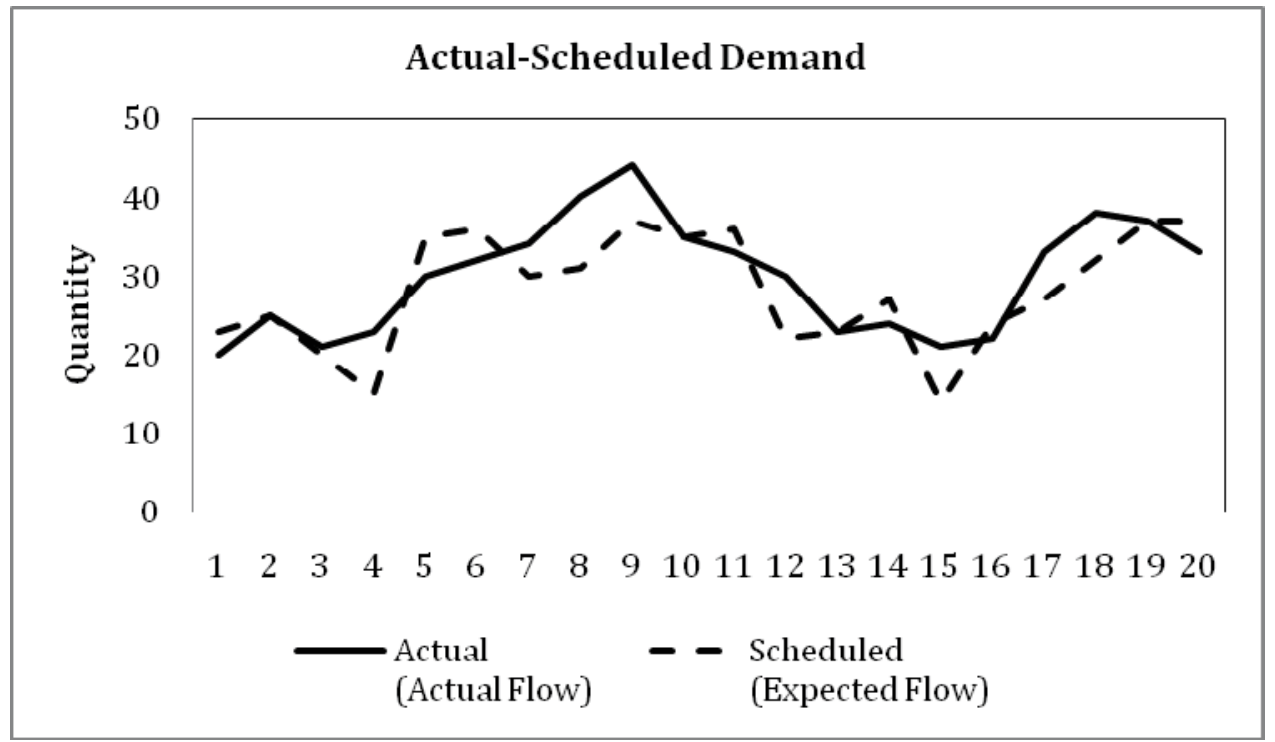

Fig. 4. Actual and scheduled demand values.

\begin{tabular}{|c|c|c|c|}
\hline \multirow[t]{2}{*}{ Time/month } & \multicolumn{2}{|c|}{ Demand level } & \multirow{2}{*}{$\begin{array}{c}\text { Variation } \\
\text { (actual-scheduled) }\end{array}$} \\
\hline & $\begin{array}{c}\text { Actual } \\
\text { (actual flow) }\end{array}$ & $\begin{array}{c}\text { Scheduled } \\
\text { (expected flow) }\end{array}$ & \\
\hline 1 & 20 & 23 & -3 \\
\hline 2 & 25 & 25 & 0 \\
\hline 3 & 21 & 20 & 1 \\
\hline 4 & 23 & 15 & 8 \\
\hline 5 & 30 & 35 & -5 \\
\hline 6 & 32 & 36 & -4 \\
\hline 7 & 34 & 30 & 4 \\
\hline 8 & 40 & 31 & 9 \\
\hline 9 & 44 & 37 & 7 \\
\hline 10 & 35 & 35 & 0 \\
\hline 11 & 33 & 36 & -3 \\
\hline 12 & 30 & 22 & 8 \\
\hline 13 & 23 & 23 & 0 \\
\hline 14 & 24 & 27 & -3 \\
\hline 15 & 21 & 14 & 7 \\
\hline 16 & 22 & 24 & -2 \\
\hline 17 & 33 & 27 & 6 \\
\hline 18 & 38 & 32 & 6 \\
\hline 19 & 37 & 37 & 0 \\
\hline 20 & 33 & 37 & -4 \\
\hline
\end{tabular}

Table 1 . The variations between actual and scheduled demand values. 


\section{State definition}

A state is what the system is doing and a system can be in one or more states. For this example the discrete random variables occur in two states: namely, "in control" and "out of control". The "in control" states include planned or scheduled states and the "out of control" states include unplanned or unscheduled states. The system is said to be "in control", if the variations between actual and scheduled values of the demand equal zero and all positive and negative variations indicate "out of control" states. The character " $x$ " represents the variation values. The state definitions are illustrated in table 2 .

\begin{tabular}{|c|c|l|}
\hline State Description & $\begin{array}{c}\text { Quantitative Differences }(x) \\
\text { (Actual-Predicted) }\end{array}$ & \multicolumn{1}{|c|}{ Definition } \\
\hline $\begin{array}{c}\text { "In Control State (ICS)" / } \\
\text { scheduled }\end{array}$ & 0 & $\begin{array}{l}\text { No variation between the } \\
\text { expected and actual demand } \\
\text { values, acceptable. }\end{array}$ \\
\hline $\begin{array}{c}\text { "Out of Control State } \\
(\mathrm{OCS}) \text { " / unscheduled }\end{array}$ & $>0$ & $\begin{array}{l}\text { Positive variations which has to } \\
\text { be taken under control, not- } \\
\text { acceptable. }\end{array}$ \\
\cline { 2 - 4 } & & $\begin{array}{l}\text { Negative variations which has } \\
\text { to be taken under control, not- } \\
\text { acceptable. }\end{array}$ \\
\hline
\end{tabular}

Table 2. The state definition.

\section{Creating a probability distribution and data analyze}

In order to calculate complexity based on entropy approach, a probability histogram is created to analyze the measurement results. Therefore, definition of the state's intervals is necessary. A state interval can be chosen according to structure of the problem which will be analyzed. According to structure of the variation, one in control state (ICS) and four out of control states (OCS) with chosen upper and lower state's bounds are proposed in this study.

\begin{tabular}{|c|c|c|c|c|}
\hline State interval & $\begin{array}{c}\text { State } \\
\text { description }\end{array}$ & $\begin{array}{c}\text { Variation } \\
\text { manageability }\end{array}$ & $\begin{array}{c}\text { Complexity } \\
\text { cost level }\end{array}$ & Countermeasures \\
\hline 0 & ICS & - & - & \multirow{5}{*}{$\begin{array}{l}\text { - Improving } \\
\text { information and } \\
\text { material flows } \\
\text { - corrective and } \\
\text { preventive actions } \\
\text { - communication and } \\
\text { continuous training }\end{array}$} \\
\hline$+6 \leq x \leq+10$ & OCS1 & $\begin{array}{c}\text { very difficult to } \\
\text { manage with serious } \\
\text { consequences }\end{array}$ & Cost Level 1 & \\
\hline$+1 \leq x \leq+5$ & OCS2 & $\begin{array}{c}\text { manageable by taking } \\
\text { certain steps with } \\
\text { suitable policy }\end{array}$ & Cost Level 2 & \\
\hline$-5 \leq x \leq-1$ & OCS3 & $\begin{array}{c}\text { manageable by taking } \\
\text { certain steps with } \\
\text { suitable policy }\end{array}$ & Cost Level 3 & \\
\hline$-10 \leq x \leq-6$ & OCS4 & $\begin{array}{c}\text { very difficult to } \\
\text { manage with serious } \\
\text { consequences }\end{array}$ & Cost Level 4 & \\
\hline
\end{tabular}

Table 3. State categorisations and their effects on complexity management. 
The criterion of complexity analyzing is illustrated in table 3 . These criterions can be different regarding the structure of problems or organizations. Each state interval has its own complexity cost level according to its manageability to be considered. The states that are very far from 'under control' states have to be more costly than that are nearly 'under control' with respect to complexity management. The more divergence to an expected value of a state, the greater the complexity and its costs. Therefore, cost levels 1 and 4 are the larger than cost levels 2 and 3. According to difficulty in management and cost level, countermeasures are required with respect to aiming to reduce or avoid complexity by corrective and preventive actions, improved communication and continuous training from a point of view of complexity management. The cost value for "in control" state (ICS) is zero (or very near zero) and there is no need to take any corrective action in this case study. However, it can be still improved by some actions to manage better.

Two statements I and II are considered for the complexity measurement. Statement I represents the original frequencies values and statement II represents the exchanged frequencies values to show the superiority of the new proposed complexity measure. Based on the calculation of the corresponding frequencies for each state interval and their probability distributions in the system, classical and new proposed structural complexity are calculated by equations 2 and 5 and operational complexity by equations 3 and 6 . The results are seen in table 4 . The deviation values $d_{i j}$ are considered mid range of the state intervals in equations 5 and 6.

\begin{tabular}{|c|c|c|c|c|c|c|c|c|c|}
\hline \multicolumn{10}{|c|}{ Complexity Results of Actual-Scheduled Demand } \\
\hline \multicolumn{2}{|c|}{ State } & \multicolumn{2}{|c|}{ Frequency } & \multicolumn{2}{|c|}{ Probability } & \multirow{2}{*}{\multicolumn{2}{|c|}{$\begin{array}{c}\begin{array}{c}\text { Complexity/ } \\
\text { Entropy }\end{array} \\
\text { (I) } \\
I_{(s)}=-\sum_{i=1}^{M} \sum_{j=1}^{N} p_{i j} \log _{2} p_{i j}\end{array}$}} & \multirow{2}{*}{\multicolumn{2}{|c|}{$\begin{array}{c}\begin{array}{c}\text { Complexity/ } \\
\text { Entropy }\end{array} \\
\text { (II) } \\
{ }_{(s)}=-\sum_{i=1}^{M} \sum_{j=1}^{N}\left[\log _{2} p_{i j}\right]_{i j} p_{i j}\end{array}$}} \\
\hline \multirow[t]{2}{*}{ Description } & \multirow[t]{2}{*}{ Interval } & \multirow[t]{2}{*}{ (I) } & \multirow[t]{2}{*}{ (II) } & \multirow[t]{2}{*}{ (I) } & \multirow[t]{2}{*}{ (II) } & & & & \\
\hline & & & & & & Classical & New & Classical & New \\
\hline ICS & 0 & 4 & 4 & 0,20 & 0,20 & 0,00 & 0,00 & 0,00 & 0,00 \\
\hline OCS1 & $+6 \leq x \leq+10$ & 3 & 3 & 0,15 & 0,15 & 0,41 & 3,28 & 0,41 & 3,28 \\
\hline OCS2 & $+1 \leq x \leq+5$ & 2 & 2 & 0,10 & 0,10 & 0,33 & 1,00 & 0,33 & 1,00 \\
\hline OCS3 & $-5 \leq x \leq-1$ & 7 & 4 & 0,35 & 0,20 & 0,53 & 1,59 & 0,46 & 1,39 \\
\hline OCS4 & $-10 \leq x \leq-6$ & 4 & 7 & 0,20 & 0,35 & 0,46 & 3,72 & 0,53 & 4,24 \\
\hline Structural C & omplexity & & & & & 1,74 & 9,59 & 1,74 & 9,91 \\
\hline Operational & Complexity & & & & & 1,39 & 7,67 & 1,39 & 7,93 \\
\hline
\end{tabular}

Table 4. Complexity values of actual-scheduled demand. 
In order to illustrate the superiority of the new proposed measure, a small change on the data is considered. Therefore, the frequency value, (7) of OCS3 (" $-5 \leq x \leq-1$ ") is exchanged with the value (4) of OCS4 (" $-10 \leq x \leq-6$ ") from the data of statement I, (highlighted by italic in statement II) and complexity values for exchanged values (statement II) are calculated again according to classical and new proposed approaches which are shown in table 4.

According to outcome of the results, classical entropy approaches do not indicate any change on results after the frequency exchange. However, the new proposed complexity measures indicate some changes on the results due to the deviation value from the expected value $\left(d_{i j}\right)$.

Although the classical complexity measures do not take into consideration the deviation value from the expected value, the new proposed approach is considered with deviation value. The same probability values have the same entropy/complexity values thus the entropy is only a function of probability of different states. The new proposed measure discerns the states which are more under control than others. It can be a better indicator for complexity in supply chains. I.e. situations that are very far from being "under control" are evaluated worse as compared with those being not so far from "under control", even if their probabilities are the same. Furthermore, more divergence to an expected value (being under control state) means more difficulty to bring complexity under control and this difficulty leads to higher costs (Isik, 2010). Therefore, it is recommended that the new proposed entropic measurement is better than the classical measurement with respect to analyzing measurement results on manufacturing cost.

\section{Conclusions}

Managing increasing complexity in manufacturing is absolutely necessary to companies to compete better in global market. In order to manage complexity effectively and efficiently, it is recommended that complexity has to be defined, measured, analyzed, reduced and avoided. This study presents all of these management strategies and especially concentrates on measurability of the complexity by using Shannon's information theory. This study proposes a modification of Shannon entropy for measurement of a system complexity and proves that Shannon's entropy measure and its use in manufacturing have a drawback. In their work complexity/entropy is only a function of probability of different states. However, Isik, (2010) proposes that it is not sufficient to analyze complexity, because each state has its own complexity level in a system which has to be considered. Therefore two new complexity measures (structural and operational) are modified to analyze complexity.

\section{References}

Calinescu, A., et al., 2000. Complexity in manufacturing: an information theoretic approach. In: I.P. McCarthy and T. Rakotobe-Joel, eds. Proceedings of the conference on complexity and complex systems in industry, 19-20 September, University of Warwick, Warwick, 30-44. 
Calinescu, A., et al. 2001. Classes of complexity in manufacturing. 17th national conference on manufacturing research, 4-6 September, University of Cardiff, Cardiff, 351-356.

Deshmukh, A.V., Talavage, J.J. and Barash, M.M., 1992. Characteristics of part mix complexity measure for manufacturing systems. IEEE international conference on systems, man and cybernetics, 18-21 October, New York, USA, 1384-1389.

Deshmukh, A.V., Talavage, J.J., and Barash, M.M., 1998. Complexity in manufacturing systems. Part 1: analysis of static complexity. IIE Transactions, 30 (7), 645-655.

Frizelle, G. and Woodcock, E., 1995. Measuring complexity as an aid to developing operational strategy. International Journal of Operations and Production Management, 15 (5), 26-39.

Gove, P.B., 1986. Complexity. Webster's third new international dictionary of the English language unabridged. Massachusetts, USA: Merriam-Webster-Verlag.

Hoyle, D., 2009. ISO 9000 Quality Systems Handbook. Butterworth-Heinemann, Oxford, UK.

Isik, F. 2010. An entropy-based approach for measuring complexity in supply chains. International Journal of Production Research, 48 (12), 3681 - 3696.

Lee, H.L., Padmanabhan, V. and Whang, S., 1997a. The bullwhip effect in supply chains. Sloan Management Review, 38 (3), 93-102.

Lee, H.L., Padmanabhan, V. and Whang, S., 1997b. Information distortion in a supply chain: The bullwhip effect. Management Science, 43 (4), 546-558.

Makui A. and Aryanezhad M. B., 2003. A new method for measuring the static complexity in manufacturing, Journal of the Operational Research Society, 54(5), 555-557.

Martin, J. W. (2007). Lean Six Sigma for supply chain management: The 10-step solution process. The McGraw-Hill Companies, Inc. New York, NY.

Martínez-Olvera, C. 2008. Entropy as an assessment tool of supply chain information sharing. European Journal of Operational Research, 185 (1), 405-417.

Milgate, M., 2001. Supply chain complexity and delivery performance: an international exploratory study. Supply Chain Management: An International Journal, 6 (3), 106118.

Montgomery, C.D., Jennings, C.L., Kulahci, M., 2008. Introduction to Time Series Analysis and Forecasting (Wiley Series in Probability and Statistics). John Wiley \& Sons, Inc., Hoboken, NJ, USA.

Ronen, B. and Karp, R., 1994. An information entropy approach to the small-lot concept. IEEE Transactions on Engineering Management, 41 (1), 89-92.

Sivadasan, S., et al., 2002. An information-theoretic methodology for measuring the operational complexity of supplier-customer systems. International Journal of Operations and Production Management, 22 (1), 80-102.

Sivadasan, S., et al., 2006. Advances on measuring the operational complexity of suppliercustomer systems. European Journal of Operational Research, 171 (1), 208-226.

Shannon, C.E., 1948. A mathematical theory of communication. Bell System Technical Journal, 27, 379-423. 
Shannon, C.E., Weaver, W., 1949. The Mathematical Theory of Communication. University of Illinois Press, Chicago, IL.

Wilding, R., 1998. The supply chain complexity triangle: uncertainty generation in the supply chain. International Journal of Physical Distribution and Logistics Management, 28 (8), 599-616.

Yao, D.D., 1985. Material and information flows in flexible manufacturing systems. Material Flow, 2, 143-149. 


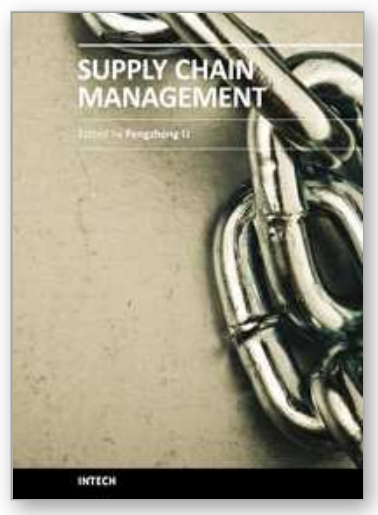

\section{Supply Chain Management}

Edited by Dr. pengzhong Li

ISBN 978-953-307-184-8

Hard cover, 590 pages

Publisher InTech

Published online 26, April, 2011

Published in print edition April, 2011

The purpose of supply chain management is to make production system manage production process, improve customer satisfaction and reduce total work cost. With indubitable significance, supply chain management attracts extensive attention from businesses and academic scholars. Many important research findings and results had been achieved. Research work of supply chain management involves all activities and processes including planning, coordination, operation, control and optimization of the whole supply chain system. This book presents a collection of recent contributions of new methods and innovative ideas from the worldwide researchers. It is aimed at providing a helpful reference of new ideas, original results and practical experiences regarding this highly up-to-date field for researchers, scientists, engineers and students interested in supply chain management.

\section{How to reference}

In order to correctly reference this scholarly work, feel free to copy and paste the following:

Filiz Isik (2011). Complexity in Supply Chains: A New Approachto Quantitative Measurement of the SupplyChain-Complexity, Supply Chain Management, Dr. pengzhong Li (Ed.), ISBN: 978-953-307-184-8, InTech, Available from: http://www.intechopen.com/books/supply-chain-management/complexity-in-supply-chains-anew-approachto-quantitative-measurement-of-the-supply-chain-complexity

\section{INTECH}

open science | open minds

\author{
InTech Europe \\ University Campus STeP Ri \\ Slavka Krautzeka 83/A \\ 51000 Rijeka, Croatia \\ Phone: +385 (51) 770447 \\ Fax: +385 (51) 686166 \\ www.intechopen.com
}

\author{
InTech China \\ Unit 405, Office Block, Hotel Equatorial Shanghai \\ No.65, Yan An Road (West), Shanghai, 200040, China \\ 中国上海市延安西路65号上海国际贵都大饭店办公楼 405 单元 \\ Phone: +86-21-62489820 \\ Fax: +86-21-62489821
}


(C) 2011 The Author(s). Licensee IntechOpen. This chapter is distributed under the terms of the Creative Commons Attribution-NonCommercialShareAlike-3.0 License, which permits use, distribution and reproduction for non-commercial purposes, provided the original is properly cited and derivative works building on this content are distributed under the same license. 